\title{
O SENTIDO DO FUTEBOL NAS AULAS DE EDUCAÇÃO FÍSICA
}

THE MEANING OF FOOTBALL IN PHYSICAL EDUCATION CLASSES

EL SENTIDO DEL FÚTBOL EN LAS CLASES DE EDUCACIÓN FÍSICA

Juliana Kanareck da Silva*, Ana Cristina Richter*, Fabio Machado Pinto*
Palavras chave:

Escolas.

Experiência.

Mediação.

Educação Física
Resumo: O trabalho investiga sentidos atribuídos ao futebol, considerando experiências extraescolares e mediações pedagógicas estabelecidas com alunos dos anos iniciais. Os dados indicam que as relações que as crianças estabelecem com o saber e com 0 aprender engendra elementos anteriores e exteriores às experiências vivenciadas na escola, associadas a família, renda, consumo, mídia, gênero, exclusão, habilidade, prazer, fama, rendimento, saúde, dor, medo, tempo livre e reconhecimento da Educação Física como disciplina escolar. Estes elementos, basilares na relação que as crianças estabelecem com o saber, sugerem a necessidade de colocar suas declarações no centro do planejamento, mediando a produção de novos sentidos para o futebol, na escola e fora dela.

\section{Keywords:}

Schools.

Experience.

Mediation.

Physical Education.

\begin{abstract}
This study investigates meanings ascribed to football, considering out-of-school experiences and pedagogical mediations established with elementary school students. Data show that children's relationship with knowledge and learning combine previous and external elements to experiences shared at school, associated to family, income, consumption, the media, gender, exclusion, skills, fun, fame, performance, health, pain, fear, free time and recognition of Physical Education as a school subject. These elements, which are basic to children's relationship with knowledge, indicate the need for considering their statements as central for planning, mediating the production of new meanings for football in and out of school.
\end{abstract}

Palabras clave:

Escuelas.

Experiencia.

Mediación.

Educación Física.
Resumen: El trabajo investiga sentidos atribuidos al fútbol, considerando experiencias extraescolares y mediaciones pedagógicas establecidas con alumnos de los años Iniciales. Los datos indican que las relaciones que los niños establecen con el saber y con el aprender engendran elementos anteriores y exteriores a las experiencias que viven en la escuela, asociadas a la familia, renta, consumo, medios de comunicación, género, exclusión, habilidad, placer, fama, rendimiento, salud, dolor, miedo, tiempo libre y reconocimiento de la Educación Física como disciplina escolar. Estos elementos, fundamentales en la relación que los niños establecen con el saber, indican la necesidad de colocar sus declaraciones en el centro de la planificación, mediando la producción de nuevos sentidos para el futbol, en la escuela y fuera de ella.
*Universidade Federal de Santa Catarina. Florianópolis, SC, Brasil. E-mail: julianakanareck@gmail.com; ana_tinaa@uol.com.br; fabiobage@yahoo.com.br.

Recebido em: 12-05-2016 Aprovado em: 31-10-2017

DOI http://dx.doi.org/10.22456/1982-8918.64681 (c) (i) () Licence 


\section{INTRODUÇÃOO}

O presente trabalho, que tematiza a relação dos alunos com a prática e aprendizado do futebol no contexto da Educação Física Escolar, decorre de uma pesquisa sobre experiências pedagógicas desenvolvidas entre março e dezembro de 2014 em uma instituição pública de ensino fundamental de Florianópolis, vinculadas ao Estágio Curricular do Curso de Licenciatura em Educação Física da Universidade Federal de Santa Catarina e ao Programa Institucional de Bolsa de Iniciação à Docência (PIBID). Nessa direção, além de professores de Educação Física e demais profissionais da escola da rede pública municipal em que a proposta foi desenvolvida, envolveu também estudantes de Licenciatura em Educação Física, bolsistas do PIBID e contou com a participação de estagiária de pós-doutorado do Núcleo de Estudos e Pesquisa Educação e Sociedade Contemporânea (NEPESC/UFSC/PPGE) na elaboração do projeto e no processo de investigação que apresentamos nas próximas páginas.

A escola na qual realizamos a pesquisa ${ }^{1}$ atende aproximadamente 500 alunos(as) do primeiro ao nono ano do ensino fundamental e localiza-se em bairro que abriga clube esportivo, centro comunitário e centro de desportos da universidade. Essas instituições fazem parte do dia a dia dos alunos desta escola, sejam as quadras abertas da universidade utilizadas para lazer, seja nos projetos sociais vinculados às instituições privadas, ou mesmo nas escolinhas de futebol oferecidas na comunidade e seu entorno. Desta forma, assumem, portanto, certa importância para a população pesquisada, à medida que usufrui estes ambientes como fonte de experiências e aprendizagens das mais diversas práticas corporais, e, também, como mediação na formação de sentidos para crianças e familiares.

No período de inserção na escola, como dito, acompanhamos o desenvolvimento de um projeto institucional que tematizou, desde uma perspectiva interdisciplinar, a Copa do Mundo de Futebol de 2014. ${ }^{2} \mathrm{O}$ projeto foi efetivado por meio de atividades que visaram conhecer e aprender sobre os países participantes da Copa do Mundo de Futebol, compreender problemas gerados por esse evento, como os enormes gastos públicos e as desocupações catastróficas. Cada turma estudou um país participante da Copa, sua cultura, gastronomia, seus jogos e brincadeiras, etc., visando:

Conhecer, debater e analisar criticamente o acontecimento mundial da Copa do Mundo de Futebol como produção cultural da humanidade, identificando aspectos históricos deste megaevento esportivo e observando e problematizando [...] os códigos do esporte de rendimento presentes em nossa sociedade (esportivização), com o propósito de perspectivar formas alternativas de relação não danificada com o corpo e com as práticas corporais, com os outros, com os objetos culturais, com o mundo, com a vida (PROJETO ESCOLAR, 2014, p. 4).

Apesar de o projeto enfatizar, para além do futebol, outras práticas da cultura, como esportes, danças, jogos e brincadeiras dos países participantes da Copa do Mundo, dos estados-sede e da cidade de Florianópolis, observamos, ao longo do período de inserção na instituição, o grande interesse dos alunos de todas as turmas pela prática do futebol. Além disso, em diagnóstico sobre o projeto, o futebol mostrou-se uma prática de grande interesse pelos alunos da escola: entre 500 alunos inicialmente entrevistados, um percentual de $75 \%$ disse gostar de futebol (PINTO; COLOMBI, 2014, p.19).

1 A investigação foi previamente autorizada pela escola com a preservação da identidade dos sujeitos investigados, respeitando princípios éticos de pesquisa. 
Esse interesse atinge não apenas essa instituição e seus atores, como também as demais escolas públicas do Brasil. Para Souza Jr. e Darido (2010, p. 924), "[...] o futebol é o conteúdo que está mais presente nas aulas de Educação Física em nosso país, contudo, o futebol 'ensinado' nestas aulas raramente ultrapassa os aspectos técnicos e o jogar livremente". Isso provoca tensões entre o professor que quer ensinar com significado essa prática da cultura (e para além de seus aspectos técnicos) e os alunos, que veem na aula de Educação Física um momento de satisfação ou de entretenimento com o jogo de futebol aspecto este que demarca uma história da Educação Física Escolar compreendida não como disciplina, mas como atividade, como tempo de recomposição para momentos mais sérios ou mero passatempo, como lembra Bracht (1999).

Busso e Daolio (2011, p.70) ressaltam que "[...] os seres humanos aprendem em família, na comunidade e outros universos socioculturais em que saberes são construídos para além da Escola". Nesse sentido, é importante considerar a relação com o futebol não apenas na escola, mas para além de seus muros, analisando a força com que invadem tempos e espaços das vidas das crianças e suas famílias, uma vez que todas essas formas culturais do futebol se configuram como saberes-objetos e objetos-saberes ${ }^{3}$ com os quais os sujeitos estabelecem relações, sendo estas mediadas pelo contexto em que se inserem (CHARLOT, 2000).

Todavia, tais relações se estabelecem, segundo Charlot (2000), mediante algo que mobiliza o sujeito, que faz nascer um desejo de aprender, que produz uma relação ativa com o mundo. Assim, para o autor, qualquer relação com o saber comporta também uma dimensão de identidade: "[...] aprender só faz sentido por referência à história do sujeito, às suas expectativas, às suas referências, à sua concepção de vida, às suas relações com os outros, à imagem que tem de si e à que quer dar de si” (CHARLOT, 2000, p. 72).

É nessa direção que se inscreve o presente trabalho, que teve como objetivo principal investigar os sentidos atribuídos pelos alunos à prática do futebol na escola e fora dela, no momento mesmo em que a instituição, por meio de projeto especial, tematizava essa prática da nossa cultura. $O$ estudo desse fenômeno implica colocar os sujeitos e suas declarações no centro da investigação (CHARLOT, 2000), num esforço de identificar problemáticas tais como a força exercida pelo futebol sobre a formação da identidade e as principais mediações na "formação do sentido" do futebol nas aulas de Educação Física e fora dela. Nessa direção, estudos da área, como os de Schneider (2004), Schneider e Bueno (2005), Pinto, Bassani e Vaz (2012), Santos e Maxiamiano (2013), que consideram as relações com o saber inclusive a partir das contribuições de Charlot -, apontam para a importância de considerar os sujeitos investigados "[...] a partir do sentido que dão às suas atividades, aprendizagens e aos resultados escolares, mas também do contexto sociocultural em que se inscrevem" (PINTO, 2012, p. 912), podendo, inclusive, "[...] constituir possibilidades de seleção e sistematização do que se ensina", conforme concluem Matos et al. (2015, p. 197).

Nas próximas páginas, após apresentar os caminhos da pesquisa, descrevemos e discutimos os dados produzidos por meio de três categorias: experiência, mediação e sentido. Concluímos o texto retomando as análises e apontando algumas conclusões e anunciando questões que podem dar continuidade à pesquisa desenvolvida.

3 Entende-se objeto-saber como um objeto no qual um saber está incorporado (por exemplo, um livro). E por Saber-objeto entende-se o próprio saber, enquanto objetivado, isto é, quando se apresenta como um objeto intelectual, como o referente de um conteúdo de pensamento" (CHARLOT, 2000, p.79). 


\section{CAMINHOS METODOLÓGICOS}

A fim de desenvolver o trabalho realizamos uma investigação de abordagem qualitativa e quantitativa, mediante questionário aplicado com alunos do $1^{\circ}$ ao $5^{\circ}$ ano do ensino fundamental e com seus familiares por meio de um software de pesquisas online (Survio) ${ }^{4}$, com perguntas padronizadas abertas e fechadas. Nas questões fechadas "[...] as respostas estão limitadas às alternativas apresentadas" e nas questões abertas a resposta é livre, "não limitada por alternativas apresentadas, o pesquisado fala ou escreve livremente sobre o tema que the é proposto" (GOLDENBERG, 2004, p. 86).

A primeira parte do questionário foi encaminhada para noventa famílias. Cinquenta e três destas famílias responderam ao questionário inicial. O bloco de perguntas dirigidas às famílias foi utilizado com o objetivo de fazer relações entre renda, escolaridade e suas associações com o sentido do futebol para os alunos, além de averiguar se as respostas dos pais se aproximavam das respostas dos filhos no que diz respeito ao futebol e às possíveis mediações que promovem 0 (des)interesse e conformam o sentido desta prática. Considera-se que a mediação dos pais e o contexto sociocultural em que se inscrevem são muito importantes na formação do sentido (das práticas corporais), visto que os sujeitos são seres sociais e singulares, ou seja, aprendem com e no mundo, por meio das relações que estabelecem e que dão sentido e significado sobre este mundo e a si mesmos, nestas mesmas relações (CHARLOT, 2005).

A segunda parte foi realizada com as crianças cujos pais enviaram as respostas, em momentos distintos, sempre após uma aula de Educação Física com o tema do futebol, ministrada pela professora da disciplina e por estagiários da licenciatura em Educação Física e bolsistas do PIBID, integrantes do projeto.

O bloco de questões direcionadas aos alunos foi construído a fim de compreender, a partir das suas próprias falas, os sentidos atribuídos à prática corporal futebol nas aulas de Educação Física e fora dela. A aplicação dos questionários evidenciou a dificuldade de muitos estudantes em responder as questões de maneira mais elaborada, principalmente os mais novos que frequentam o primeiro e o segundo ano do ensino fundamental. Contudo, essa técnica também se evidenciou positiva no sentido de coletar dados declarativos de escolares com pouca idade, pois, além de considerar o que dizem as crianças sobre suas atividades escolares e seus sentidos, permitem-nos evidenciar diferentes ou novos elementos para avançarmos nos estudos sobre os processos de mobilização e aprendizagem escolar.

Como fonte complementar utilizamos relatórios das observações das aulas de Educação Física produzidos pelos supracitados estagiários e bolsistas PIBID, ao longo do desenvolvimento do projeto "Copa de Futebol do Mundo Escolar". O projeto, desenvolvido durante o primeiro semestre de 2014, tornou as aulas de Educação Física e das demais disciplinas um local onde o futebol era um importante elemento a ser discutido e vivenciado, possibilitando uma relação interdisciplinar e interturmas e a promoção da reflexão crítica sobre a cultura esportiva.

A seguir apresentamos resultados da pesquisa focalizando as experiências dos alunos com o futebol no contexto escolar e extraescolar, as mediações que auxiliam na formação

4Survio é um software de pesquisas online gratuito que permite ao pesquisador construir seu próprio instrumento com facilidade. Dispõe de resultados expressos em tabelas e gráficos em tempo real, além de relatórios em PDF e Excel. Disponível em: <http://www.survio.com>. 
sobre o sentido do futebol para estes sujeitos e os sentidos pelos escolares a esse elemento da cultura.

\section{EXPERIÊNCIAS}

As crianças aprendem em todos os lugares, na família, no seu bairro e em todos os outros ambientes culturais por onde circulam, e, assim, para além dos muros da escola.

Conforme destaca Silva (2007), mesmo que esses outros ambientes que compõem o cotidiano infantil - instituições e instâncias culturais mais amplas do que os ambientes formais de atendimento e educação da infância - "[...] não tenham a intenção explícita de ensinar, parece óbvio que eles ensinam alguma coisa, que transmitem uma variedade de formas de conhecimento que embora não sejam reconhecidas como tais são vitais na formação da identidade e subjetividade" (SILVA, 2007, p. 140). É nesse contexto que se passa a examinar esses "outros" lugares da infância como uma forma de pedagogia, como sistemas de significação fortemente implicados na produção de identidades e subjetividades sociais e individuais e que adentram a escola.

Entre esses conhecimentos encontra-se o futebol, enquanto prática da cultura corporal amplamente difundida em nossa sociedade. Na vida extraescolar das crianças investigadas, existe uma presença marcante do futebol, sendo que 69,81\% afirmam que "praticam futebol fora da escola" e 67,90 \% alegam "gostar" de tal prática. Se considerarmos, com Lovisolo (1997), que o gosto é produzido culturalmente e não uma questão natural, inata, pode-se afirmar que os familiares investigados nesta pesquisa têm contribuído para formação do gosto pelo futebol, uma vez que a relação com tal prática é incentivada, especialmente pela mãe e pelo pai, que também oferecem recursos e equipamentos para os filhos.

Um percentual de $64,15 \%$ dos pais disse incentivar seus filhos à prática do futebol, sendo que $49,06 \%$ jogam futebol com seus(uas) filhos(as) fora da escola. Tais aspectos contribuem para a formação do gosto, que, também na fala das crianças, aparece mediado pela família. Nessa direção, quando interrogadas a respeito do motivo pelo qual gostam de futebol, as crianças responderam: "Porque meu pai gosta e eu assisto aos jogos com ele"; "Porque futebol é praticamente o primeiro esporte legal e que todo mundo pratica"; "Porque foi a primeira coisa que meu pai me ensinou"; "Porque meus irmãos gostam de jogar futebol comigo"; "Porque minha família toda gosta". Percebe-se a forte mediação dos pais, sobretudo por servir de exemplo do que fazer e do que gostar, no qual o futebol ocupa um lugar importante.

O gosto das crianças pelo futebol é também motivado pela possibilidade de profissionalização e pelo discurso performático de nossa cultura, que visa ao espetáculo, aos resultados atléticos, aos recordes, aos troféus e às vitórias. Para Souza e Máximo (2008, p. 86), "em diferentes contextos, crianças e jovens destacam o futebol como uma experiência que Ihes proporcionaria profissão ou meio de vida". Para crianças do primeiro ano, todavia, este sentido ainda é pouco mobilizador, visto sua rara presença nos depoimentos dos alunos.

Outrossim, $54,72 \%$ dos familiares compram material esportivo para os filhos, sendo que tais dados encontram correspondência com as respostas dos alunos, ao afirmarem, por exemplo, que os familiares ofertam materiais, como se pode observar nos registros dos questionários: "Tenho bola e tênis, meus pais me deram"; "Chuteira, bola, roupa de futebol. A 
chuteira ganhei da amiga da minha mãe, a roupa da mãe, a bola foi do pai"; "Caneleira, bola, chuteira, camiseta, short. Garrafinha de água. Minha mãe e meu pai que compram”.

As crianças não apenas ganham materiais, praticam e são incentivadas a praticar futebol como também acompanham o esporte nos meios midiáticos. Esse é o caso de 62,50\% das crianças investigadas, que informam assistir futebol "Na televisão, no estádio e no rádio"; "Na TV, na internet"; "Na TV, principalmente. Fui uma vez no estádio"; "Às vezes quando meu time joga eu assisto na TV ou rádio". A televisão pouco a pouco perde seu espaço para as mídias virtuais, mas ainda aparece como uma importante ferramenta de informação, que produz modos específicos de se relacionar com o futebol.

Além do contexto midiático e do contexto familiar em que a relação com o futebol é incentivada, o bairro que abriga a escola investigada dispõe de quadras, ginásios e campo de futebol "disponíveis" para a comunidade. Além disso, conta com espaços privados e projetos sociais esportivos, acessíveis às crianças desta escola. Nessa direção, os lugares mais citados pelos alunos sobre onde se pratica o futebol fora da escola são: em casa; parques; clubes; projetos; campo de futebol; quadras de esporte da universidade. Nessa direção, consideramos, com Charlot (2005), que o aprender é imbricado não apenas pela busca de um saber pelo sujeito, mas pelo contexto de um determinado ambiente social, sob formas e condições preexistentes.

\section{MEDIAÇÃO}

Quando indagadas sobre com quem aprenderam a jogar futebol, as crianças enfatizaram: "Foi o meu pai, mas eu fui aprendendo"; "Meu pai"; "Meu pai, numa quadra da UFSC"; "Eu acho que aprendi com meu padrasto"; "Foi o meu irmão e meu pai me ensinou a dar balãozinho". Em alguns casos as crianças responderam: "Meu amigo da escola"; "Comecei a jogar sozinho, depois de ganhar uma bola de um menino em uma festa"; "Eu aprendi assistindo os jogos que passam na televisão". Desta forma, observa-se que, no contexto familiar, o irmão (22,64\%) aparece nas falas dos alunos como principal mediação sobre a experiência de se aprender e jogar futebol, seguido do pai (18,86\%). Já a professora de Educação Física aparece como mediadora em $9,43 \%$, seguida de primos/amigos (7,54\%) e do padrasto (3,77\%).

Nesse sentido, apesar de a escola ter desenvolvido um projeto sobre a Copa do Mundo de Futebol e de os questionários terem sido aplicados sempre em momentos imediatamente posteriores às aulas de Educação Física que tematizaram aquela prática, ainda assim, a maior parte das crianças não reconhece o futebol como conteúdo aprendido nas aulas de Educação Física Escolar.

Contrariamente, os registros de campo tomados como fonte complementar, assim como das aulas ministradas anteriormente à aplicação dos questionários, apontam para a tematização do futebol nas aulas de Educação Física, ou seja, para o futebol como conteúdo focalizado nas aulas.

Por outro lado, quando perguntado às crianças especificamente sobre as aulas ministradas, sobre o que mais haviam gostado na aula de aprendizado do futebol, elas responderam: "Os grupos foram bem organizados"; "Gostei daquela de dominar a bola e passar". "Exercício de passe em dupla"; "Foi divertido. O jogo"; "Gostei da parte do jogo"; "Gostei dos 
passes"; "Brincadeira de chutar no gol"; "Queimada com o pé”; "Pegador com a bola no pé"; "De jogar futebol"; "Atividade de passe em roda". Quando indagadas a respeito de outros conteúdos que poderiam compor as aulas de Educação Física, também foram enfatizadas brincadeiras como pega-pega, esconde-esconde, pula corda, jogo de números, brincadeiras de correr, cabo de guerra, brincadeiras cantadas, amarelinha, entre outros que já conhecem.

A maioria das crianças não considera as aulas de Educação Física como lugares de aprendizagem e as vinculam, sobremaneira, a um espaço de diversão, de brincadeira livre. Por isso, a aula é muitas vezes concebida como um fazer, em que nem sempre o aprender está presente. Charlot (2009) ressalta a predominância da visão recreativo-formativa da Educação Física Escolar e afirma que, apesar de esta disciplina ter objetivos e conteúdos sistematizados, revela-se como um discurso que não tem impacto na escola. Para o autor:

No que tange ao espaço, a Educação Física não é escolar: as atividades desenrolam-se fora da classe. Sendo assim, o ensino da Educação Física deve respeitar características fundamentais da forma escolar num ambiente outro que não a classe [sala de aula], foco da forma escolar. Portanto, não é de se admirar que a Educação Física se confronte com contradições e que suas aulas sejam percebidas como momentos de libertação, de alívio dos constrangimentos e ganhem a forma "recreativa" (CHARLOT, 2009, p. 234).

A Educação Física, que tenta se firmar no âmbito escolar e busca sua legitimidade como todas as outras disciplinas consideradas "sérias", também enfrenta dificuldade com os alunos, na medida em que é vista muitas vezes como "tempo livre" ou "momento de descanso do intelecto". Neste sentido, os alunos não veem a Educação Física como um local onde se pode aprender sobre futebol, mas, sim, somente como um lugar em que se pode jogar futebol livremente. Exemplo disso pôde ser observado durante o estágio supervisionado obrigatório, em uma turma de primeiro ano do ensino fundamental:

No momento das explicações um aluno pediu à professora para falar e então questionou: "Professora, podemos fazer Educação Física agora?", e a professora respondeu: "Nós já estamos na Educação Física", e o aluno novamente questionou: "Mas, professora, quero ir para a quadra brincar" (Relatório de Educação Física, 2014).

Talvez possamos dizer que, para as crianças, o aprendizado do futebol decorre essencialmente de ações externas às aulas de Educação Física, trazendo consigo o sentido da diversão em múltiplos espaços ou ambientes. Portanto, apesar de o futebol ser conteúdo pertinente à Educação Física, parece se apresentar como uma prática naturalizada para as crianças, que não "necessita" da escola para ser aprendida, instituindo-se como sua cultura primeira.

\section{SENTIDOS}

O futebol hoje é compreendido como um importante fenômeno sociocultural, com demandas políticas, econômicas e ideológicas (MACAGNAN; BETTI, 2014), despertando o interesse em praticar e acompanhar este esporte pela sociedade:

0 grande interesse dos espectadores por esse esporte, nos dias de hoje, devese à necessidade que povos de todo o mundo têm de atividades de lazer que propiciem um tipo de excitação que não se encontra mais nas sociedades atuais. E o futebol, pela sua configuração especial, propiciaria 0 atendimento a esta necessidade (MACAGNAN; BETTI, 2014, p. 315) 
Nos anos iniciais da escola estudada, pouco mais de $5 \%$ demonstram desinteresse pela sua prática nas aulas de Educação Física. Uma pequena diferença nos resultados das meninas indica que elas apresentam o menor interesse, ou seja, 39\% têm "mais ou menos" ou "não têm" interesse pelo futebol. Entre os meninos apenas uma resposta desinteressada pela prática e quatro "mais ou menos", sendo que um menino do quarto ano informou que: "Não gosto porque eu tenho medo de me machucar. Um dia quase quebrei a perna por causa do futebol". As quatro respostas sobre o gostar "mais ou menos" advêm de crianças que frequentam o primeiro e o segundo ano. Para elas: "É difícil de chutar no gol e defender, e se pegar em mim machuca"; "Eu não sei jogar futebol"; "Porque ninguém passa a bola para mim"; "É muita correria. Eu não sei nem pegar a bola direito. Eu sei driblar bem pouquinho".

Outro dado pertinente é o crescente interesse pelo futebol, que começa com 50\% dos alunos do primeiro ano e chega a $75 \%$ no quarto ano. Nota-se também um crescente interesse pelo futebol à medida que a renda e a formação dos pais aumenta. Os alunos mais pobres pertencentes a famílias com menos escolaridade estariam "menos interessados", "mais ou menos interessados", ou "não interessados". O percentual de alunos menos interessados encontra-se, sobretudo, entre aqueles que são mais novos e com menor escolaridade, pertencentes a famílias com menor renda e menor escolaridade, filhos de pais que não incentivam, não compram equipamentos e não praticam futebol com os filhos fora da escola. São eles que também dizem não gostar de futebol nas aulas de Educação Física.

Não obstante, os relatórios das observações das aulas de Educação Física durante o projeto Copa de Futebol realizado nessa escola mostram alguns casos de preferência por essa prática corporal no primeiro ano do ensino fundamental. Nestes casos, o futebol aparece como um jogo que desperta prazer e diversão, sendo que a Educação Física teria "obrigação" de disponibilizar essa prática para os(as) alunos(as), mas não propriamente abordar pedagogicamente, tal como os demais conteúdos disciplinares. Esta visão pode ser explicada, como dito acima, pelo fato de a Educação Física ser entendida pelos alunos como um momento de libertação dos corpos e da mente.

Pinto, Bassani e Vaz (2012), em estudo que teve como objetivo compreender os sentidos atribuídos às práticas corporais aprendidas fora da escola, sugerem o prazer como um dos elementos que atribuem sentido às práticas corporais dos alunos, sendo o futebol uma delas. Para os autores:

Indagar sobre o sentido é o mesmo que interrogar sobre os móbiles que fazem os estudantes agirem, o que implica também considerar aqueles que não são imediatamente fruto de reflexão, mas que podem atuar em plano mais espontâneo, ou até mesmo irrefletido (PINTO; BASSANI; VAZ, 2012, p. 911).

Portanto, devemos nos perguntar: quais são os móbiles que ativam a ação dos alunos no sentido da aprendizagem? Charlot (2000, p. 67) escreve que a questão da mobilização do sujeito, da sua entrada em atividade intelectual, "[...] parece central na problemática da relação com o saber: por que (motivo) e para que fim (fim, resultado) o sujeito se mobiliza? Que desejo sustenta esta atividade?" Para o autor, o que mobiliza o sujeito está relacionado com o desejo, com aquilo que nos impulsiona a fazer algo.

A categoria "não gosto", encontrada em 16,9\% das respostas do grupo pesquisado, apresenta o descontentamento pela prática do futebol, sugerindo fatores de exclusão, de gênero e de medo, como, por exemplo, "Não gosto, porque eu me machuco muito"; "Porque é uma 
coisa meio de menino, meio chato e porque às vezes a gente se machuca caindo"; "Não gosto porque eu tenho medo de me machucar."; "Porque ninguém passa a bola para mim".

Especificamente para as meninas, o sentido do futebol está mais associado a exercitar-se e estar em grupo, ainda que elas sejam menos interessadas e que expressem suas razões por motivos como o medo de se machucar, enquanto os meninos reclamam da sua exclusão e de não receber a bola, como no exemplo: "Porque às vezes eu acho o futebol um pouco legal, às vezes os amigos nossos passam a bola para nós, mas quando eles não passam, não é legal". Além disso, os meninos relacionam a pratica a diversão e aprendizagem de habilidades, por exemplo, "É divertido. Aprende educação. Aprende domínio"; "Porque eu gosto de fazer gol".

São os alunos com maior tempo de escolarização que associam a prática do futebol ao futuro como atletas ou, por razões sociais, estar em grupo: "Porque quando eu crescer eu quero ser goleiro"; "Porque a gente também pode ser atleta de futebol. Também tem troféu de futebol e eu quero ganhar."; "Porque é legal, e vai que um dia eu vire uma atleta"; "Porque tem um time para passar a bola para o outro"; "É difícil explicar, porque é um esporte legal, porque se pratica em grupo".

Alunos que são incentivados a jogar e cujos pais jogam futebol com eles fora da escola salientam que aprendem futebol: "Porque é uma coisa que eu corro muito, eu gosto de bola e mistura o aprendizado"; "Porque desenvolve a capacidade do passe de bola e para dominar a bola"; "Porque é divertido e faz a pessoa aprender a jogar"; "Porque ele ensina ver os países, podemos jogar, podemos jogar pelos países que acontecem a Copa"; "Porque a gente aprende a perder e vencer".

A mediação, que envolve a relação com outrem, exerce demasiada importância na formação do sentido, e a família, como dito, aparece como principal responsável pela aproximação das crianças com o futebol.

Macagnan e Betti (2014) atentam ainda para uma forte relação que se tem entre 0 futebol e o processo de formação do indivíduo, que ocorre primeiramente na família, porém, nela, o contexto escolar cumpre também forte participação. Além disso, a mídia, que exerce grande influência sobre o contexto escolar e o entendimento que os escolares têm do esporte e do ser esportista, exerce também importante participação sobre este processo de formação do sentido, à medida eles transmitem discursos destacando apenas as qualidades e atributos dos jogadores profissionais de futebol, tornando-os seres especiais e referências de comportamento (MACAGNAN; BETTI, 2014). Assim, torna-se significativo desvendar as práticas e representações do futebol entre os escolares, uma vez que ele perpassa suas vidas, seja como prática na escola ou fora da escola, mas, também, como representação simbólica, por meio das mídias, família, etc. (MACAGNAN; BETTI, 2014).

Desta forma, percebe-se que muitos são os sentidos atribuídos a essa prática corporal, e que o interesse pelo futebol dentro da escola e nas aulas de Educação Física se torna mais significativo à medida que as experiências com essa prática se fazem mais presentes no cotidiano dos alunos, em sua maioria no âmbito extraescolar. A mediação do adulto nessas experiências implica fortemente na formação do sentido.

\section{CONSIDERAÇÕES FINAIS}

No decorrer desta pesquisa observamos que as relações que as crianças estabelecem com o saber e com o aprender na escola aparecem implicadas por elementos anteriores e 
exteriores às experiências vivenciadas nesse espaço de educação formal, frequentemente desconsiderados no âmbito do planejamento e da reflexão pedagógica, mas que se constituem como aspectos fundamentais do fracasso ou do êxito escolar. As experiências extraescolares com o futebol, para as crianças investigadas, ganharam lugar destacado nesta pesquisa, encontrando-se na família um importante locus de mediação, seguido da mídia e todos os outros contextos em que a criança está inserida, revelando-nos que as relações sociais se instituem como meios pelos quais se constituem os desejos e projetos destes escolares, onde o futebol aparece como uma prática dotada de sentido que orienta suas preferências, gostos e escolhas.

Dada a sua hegemonia, a intensidade com que essa prática se faz presente no seu cotidiano, os alunos tendem a desconsiderá-lo como saber a ser aprendido na escola. Tratase de uma questão problemática, pois o futebol, neste contexto, é sobrevalorizado enquanto prática de rendimento, orientada por princípios como o desempenho máximo, o sacrifício, a superação dos limites do corpo, a competição, que se tornam naturalizadas e reguladoras das relações humanas. Tal visão a respeito do futebol se recoloca nas falas das crianças quando atribuem ao futebol à possibilidade de ascensão profissional, de conquistar troféus ou de tornar-se famoso, demonstrar habilidade e competir. Este sentido atribuído ao futebol pode ser produtor de violência ou de exclusão, como é caso de crianças menos habilidosas que acabam por serem excluídas, como os pequenos, que dizem, por exemplo, "os outros não me deixam jogar", ou "eu sempre fico de fora", aspectos estes contrários à formação humana.

O discurso da atividade física e da promoção da saúde, embora em menor escala, também aparece nas vozes das crianças, remetendo à explosão discursiva presente em nossa sociedade que, de modo perverso, acaba por exigir das pessoas o controle sobre a sua própria saúde desconsiderando, por exemplo, os determinantes sociais que provocam sua debilidade. Para Charlot (2000), no entanto, quando os alunos entram na escola devem encontrar novos tipos de relação com o saber e estes devem se apoiar nas relações já construídas numa perspectiva descontinuísta. Neste caso, ao reconhecer a importância sobre os sentidos dotados pelos alunos, a escola torna-se um espaço também responsável pela formação de novos sentidos, isto é, para além daqueles veiculados, vivenciados, consumidos sem reflexão em nossa sociedade.

Houve, também, uma pequena parcela de crianças que citou o desinteresse pela prática do futebol, atribuindo sentidos diferentes daqueles que demonstram gostar, como, por exemplo, o medo de se machucar, as relações de gênero, sentimentos de medo e dor, entre outros. Ou seja, tais sentidos são atribuídos como justificativa de tal desinteresse e dizem respeito às emoções, a sentimentos e relações historicamente situadas e muitas vezes desconsideradas em nossa prática pedagógica. Para Vigotski (2001, p. 139),

Toda emoção é um chamamento à ação ou uma renúncia a ela. Nenhum sentimento pode permanecer indiferente e infrutífero no comportamento. As emoções são esse organizador interno das nossas emoções, que retesam, excitam, estimulam ou inibem essas ou aquelas reações. Desse modo, a emoção mantém seu papel de organizador interno do nosso comportamento.

Outro aspecto relacionado ao sentido do futebol para as crianças aparece associado à cultura escolar no que se refere à Educação Física, que busca por se legitimar como disciplina curricular, mas que ainda se institui como atividade, como tempo livre e, portanto, "dispensada" 
de mediação. Daí também as crianças não reconhecerem o futebol como conteúdo a ser aprendido na escola. Junta-se a isso o fato de a Educação Física Escolar extrapolar a sala de aula, legitimada como espaço de aprendizagem de conteúdos sempre mais sérios, pois vinculados ao intelecto e não às questões do corpo. Nesta direção, o futebol ganha sentido somente como diversão, entretenimento. Tal visão ganha relevo quando se trata das crianças dos primeiros anos do ensino fundamental, ao sugerirem que as aulas de Educação Física deveriam contemplar brincadeiras recreativas.

Nessa direção, dar voz aos alunos pode ser uma importante orientação para a prática pedagógica, favorecendo a compreensão dos sentidos da mobilização dos escolares nas práticas e aprendizagens, de modo a poder melhor auxiliá-los durante as aulas por meio de mediações mais reflexivas, e consequentemente, contribuir para construção de novos sentidos às práticas corporais. Em outros termos, trata-se da possibilidade de construir referências a respeito das experiências vivenciadas e, ao mesmo tempo, de se relacionar reflexivamente com elas, com os outros e com o mundo.

\section{REFERÊNCIAS}

BRACHT, Valter. A constituição das teorias pedagógicas da Educação Física. Cadernos Cedes, v. 19, n. 48, p. 69-88, ago. 1999.

BUSSO, Gilberto Leandro; DAOLIO, Jocimar. O jogo de futebol no contexto Escolar e extraescolar: Encontro, confronto e atualização. Revista Brasileira de Ciências do Esporte, v.33, n.1, p.69-86, jan./mar. 2011.

CHARLOT, Bernard. Da relação com o saber: elementos para uma teoria. Porto Alegre: Artmed, 2000.

CHARLOT, Bernard. Relação com o saber, Formação de Professores e Globalização: questões para a educação hoje. Porto Alegre: ARTMED, 2005.

CHARLOT, Bernard. Ensinar a educação física ou ajudar o aluno a aprender o seu corpo-sujeito? In: DANTAS JUNIOR, Hamilcar; KUHN Roselaine; DORENSKI, Sérgio (Org.). Educação física, esporte e sociedade: temas emergentes. São Cristóvão: Editora da UFS, 2009. v.3, p. 231-246.

GOLDENBERG, Mirian. A arte de pesquisar: como fazer pesquisa qualitativa em Ciências Sociais. 8. ed. São Paulo: Record, 2004.

LOVISOLO, Hugo. Estética, esporte e educação física. Rio de Janeiro: Sprint, 1997.

MACAGNAN, Leandro Del Giudice; BETTI, Mauro. Futebol: Representações e Práticas Escolares de fazer ensino fundamental. In: Revista brasileira de Educação Física e Esporte, v.28, n. 2, p. 315327, 2014.

MATOS, Juliana Martins Cassani et al. Conteúdos de Ensino da Educação Física Escolar: saberes compartilhados nas narrativas docentes. Revista de Educação Física/ UEM, v. 26, n. 2, p. 181-199, jun. 2015.

PINTO, Fábio Machado. Les pratiques corporelles et le rapport aux savoirs: logiques et processus de mobilisation à l'apprentissage des pratiques corporelles en éducation physique scolaire au Brésil. 2012. 403 f. Tese (Doutorado)- Université Paris 8, Paris, 2012. 
PINTO, Fábio Machado; BASSANI, Jaison José; VAZ, Alexandre Fernandez. Sentidos das práticas corporais fora da escola para alunos dos anos iniciais do ensino fundamental. Revista Brasileira de Ciências do Esporte, v. 34, n. 4, p. 909-923, out./dez. 2012.

PINTO, Fábio Machado; COLOMBI, Gisela. Conjuntura da EBM Beatriz de Souza Brito: formação docente e educação física. Cadernos de Formação RBCE, v. 4, n. 1, p. 9-12, 2013.

SANTOS, Wagner dos; MAXIMIANO, Francine de Lima. Memórias Discentes EM Educação Física na Educação Básica: práticas avaliativas. Movimento, v. 19, n. 2, p. 79-101, abr./jun. 2013.

SCHNEIDER, Omar. A Educação Física e as relações epistêmicas com o saber: uma incursão no pensamento de Bernard Charlot. In: ENCONTRO FLUMINENSE DE EDUCAÇÃO FÍSICA ESCOLAR, 8., 2004. Anais... Niterói: Universidade Federal Fluminense, 2004. v. 1, p. 44-46.

SCHNEIDER, Omar; BUENO José Geraldo Silveira. A relação dos alunos com o saber compartilhado nas aulas de Educação Física. Movimento, v.11, n.1, p. 23-46, 2005.

SILVA, Tomaz Tadeu da. Documentos de identidade: uma introdução às teorias do currículo. Belo Horizonte: Autêntica, 2007.

SOUZA JÚNIOR, Osmar Moreira; DARIDO, Suraya Cristina. Refletindo sobre a tematização do futebol na Educação Física escolar. Motriz, v.16, n.4, p. 920-930, 2010.

SOUZA, Camilo Araújo Máximo et al. Difícil reconversão: futebol, projeto e destino em meninos brasileiros. Horizontes Antropológicos, v. 14, n. 30, p. 85-111, dez. 2008.

VIGOTSKI, Lev Semyonovich. Psicologia Pedagógica. São Paulo: Martins Fontes, 2001.

Apoio:

CNPq, Programa de Pós-doutorado Júnior (PDJ/UFSC/CNPq); MEC/CAPES, Programa Institucional de Bolsas de Iniciação Docente (PIBID). 